\title{
MANIFESTAÇÕES PATOLÓGICAS DE PARTE DO EDIFÍCIO NO CONJUNTO HABITACIONAL EM PAULISTA-PE
}

\author{
FIGUEIRÊDO, AUGUSTO \\ Engenheiro Civil \\ Instituto Federal de Pernambuco \\ Pernambuco; Brasil \\ augusto@rochaleal.com
}

\author{
SILVA, ÂNGELO JUST DA COSTA \\ Professor Doutor \\ UNICAP \\ Pernambuco; Brasil \\ angelo@tecomat.com.br
}

\author{
LIMA, MIÉLIX JOSÉ SEVERO \\ Químico Industrial e Mestrando \\ Instituto Tecnológico de Pernambuco \\ Pernambuco; Brasil \\ mielixlima@recife.ifpe,edu.br
}

\author{
PINTO, JOSÉ WANDRLEY \\ Professor Mestre \\ Instituto Federal de Pernambuco \\ Pernambuco; Brasil \\ josepinto@recife.ifpe.edu.br \\ SANTOS, ANDRÉ MIRANDA \\ Mestre em Engenharia Civil \\ Insituto Federal de Pernambuco \\ Pernambuco; Brasil \\ dedester@gmail.com
MOTA, JOÃO MANOEL F.
Professor Doutor
Instituto Federal de Pernambuco
Pernambuco; Brasil
joaomota@recife.ifpe.edu.br

\section{RESUMO}

Objetivou-se neste trabalho analisar as patologias em peças de concreto armado de uma edifício localizado no Bairro de Maranguape I, na cidade de Paulista/PE. O estudo delimita-se a estruturas de concreto armado que sustenta a escada e reservatório superior de água. Como método de investigação, buscou-se realizar: (a) ampla inspeção visual com acervo fotográfico para estabelecer os níveis de deterioração estabelecido pelo boletim 162 do CEB; (b) ensaios de carbonatação; (c) ensaios de íons cloretos livres. Nesse contexto, poder-se-ia melhor apontar um diagnostico provável das causas da deterioração das estruturas. Não obstante, os elementos estruturais foram caracterizados quanto ao seu tempo em serviço, resistência à compressão, tipo de revestimento, detalhes específicos dos danos. Os resultados indicaram que a maioria das peças precisa de intervenções imediatas devido aos elevados níveis de degradação.

Palavras-chave: Corrosão; Deterioração; Carbonatação e cloretos.

\begin{abstract}
The objective of this work was to analyze the pathologies in reinforced concrete pieces of a building located in the neighborhood of Maranguape I, in the city of Paulista / PE. The study is limited to reinforced concrete structures that support the ladder and upper water reservoir. As an investigation method, we sought to carry out: (a) extensive visual inspection with a photographic collection to establish the levels of deterioration established by CEB bulletin 162; (b) carbonation tests; (c) free chloride ion tests. In this context, it would be better to point out a probable diagnosis of the causes of the deterioration of the structures. However, the structural elements were characterized in terms of their service life, resistance to compression, type of coating, specific details of the damage. The results indicated that most parts need immediate intervention due to the high levels of degradation.

Keywords: Corrosion; Deterioration; Carbonatation and chlorides.
\end{abstract}




\section{INTRODUÇÃO}

O município do Paulista está localizado ao norte da capital pernambucana e faz parte da região metropolitana do Recife. Segundo dados do instituto brasileiro de geografia e estatística, ocupa uma área de $97,31 \mathrm{~km}^{2}$ com população estimada de 328.353 habitantes. O bairro de Maranguape I em Paulista/PE é banhado pelo rio Paratibe e o Canal das Tintas. Tem como principal via de acesso à rodovia PE-22 e limita-se com os bairros de Maranguape II (ao norte), Fragoso (ao sul), Parque do Janga e Jardim Maranguape (ao leste) e com os bairros do Nobre e Torres Galvão (ao oeste).

Segundo dados da defesa civil do Paulista, o município possui 261 unidades de edificações do tipo "caixão" (com modelo similar ao estudo), estando essas edificações espalhadas pelos bairros de Maranguape I, Jardim Maranguape, Arthur Lundgren I e Arthur Lundgren II, contendo 8.352 apartamentos e com uma população estimada residente nesse tipo de edificação de 33.408. Além disso, existem 111 prédios do tipo caixão em todo o bairro de Maranguape I, totalizando 3.552 apartamentos e uma população estimada de 14.208 pessoas vivendo nesse tipo de edificação ao longo de todo o bairro. As unidades residenciais do tipo "caixão" (nome atribuído a prédios com esse formato, haja vista a fachada ter um volume análogo a uma caixa) encontradas ao longo de todo o bairro de Maranguape I, têm projeto padrão (planta baixa dos prédios com formato de "H"), sendo compostos por um pavimento térreo mais três pavimentos tipo, totalizando 32 apartamentos. Esta edificação possui duas escadas em concreto armado, contendo um reservatório superior de água em cada estrutura da escadaria (figuras 1 e 2).

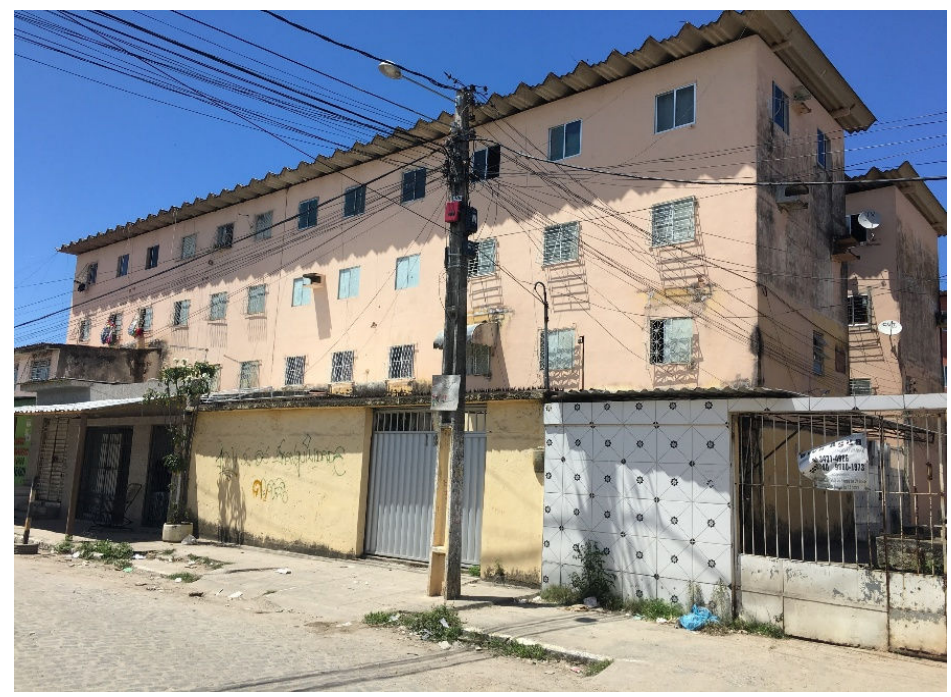

Figura 1 - Modelo representativo da edificação estudada - parte lateral (FIGUEIRÊDO, 2019)

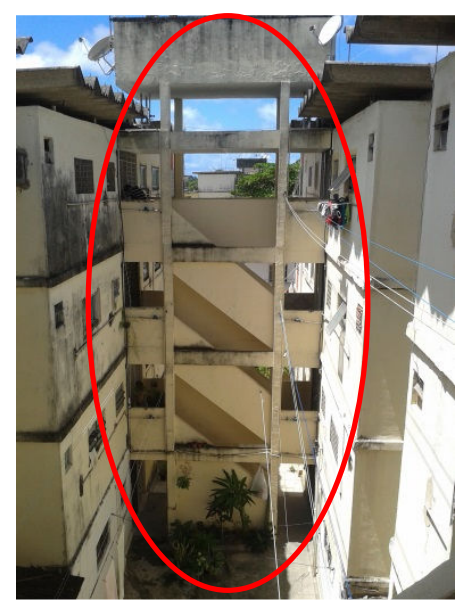

Figura 2 - Modelo representativo de estrutura da escada e reservatório superior de concreto armado estudado (FIGUEIRÊDO, 2019) 
Portanto, este trabalho tem o objetivo de apresentar as manifestações patologias encontrada na estrutura de concreto armado das escadas e reservatórios superior de água de um prédio (estudo de caso) localizado no conjunto habitacional de Paulista/PE. Vale destacar que o prédio estudado à baila, possui paredes e lajes de concreto.

Podem-se apresentar alguns estudos relevantes acerca da corrosão de armaduras em peças de concreto armado, uma vez que esta manifestação patológica é por demais identificada em estruturas de concerto armado. Nessa premissa, Helene (1992) mostrou que dentre os danos ocorrentes neste compósito, a corrosão das armaduras excede em mais de $20 \%$. Não obstante, neste mesmo contexto, pode-se verificar índices catalogados de corrosão de armaduras mais significativos em outras regiões do Brasil, como no Rio Grande do Sul [mais de 30\% (GALVÃO, 2004)], e, em Recife [próximo a 65\% (ANDRADE, 1997)].

A NBR 6118:2003 estabeleceu critério concernente a durabilidade, onde a barreira física (cobrimento da armadura) tornou-se fundamental. Entretanto, além da importância da espessura dessa camada, não se pode deixar de relevar a importância da mínima porosidade possível, haja vista que a mitigação do acesso ao concreto de agentes deletérios (cloretos, $\mathrm{CO}_{2}$, sulfatos, umidade, ácidos, sais etc.), controla ataques químicos que aguçam a baixa da alcalinidade, da corrosão, reação álcali-agregado etc. Portanto, aspectos físicos e químicos que promovam a proteção da camada passivadora das armaduras, devem imperativamente ser considerado desde a etapa do projeto (HELENE, 1997; MOTA et al., 2011).

Inúmeras edificações apresentam manifestações patológicas em intensidade e incidência significativas, acarretando elevados custos para sua correção. Sempre há comprometimentos dos aspectos estéticos e, na maioria das vezes, redução da capacidade resistente. Em geral, manifestações patológicas são evolutivas e tendem a agravar com o passar do tempo. Correções preventivas podem ser mais duráveis, mais efetivas, mais fáceis de execução e muito menos oneroso (HELENE, 1992). A Figura 8 apresenta os custos hipotéticos, conhecido como lei dos cinco ou lei de Sitter (1984), onde mostra que os custos das intervenções crescem em função do tempo e segundo uma progressão geométrica de razão cinco.

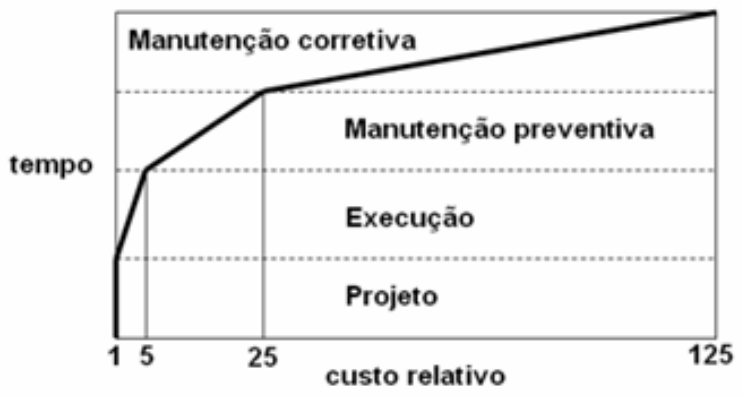

Figura 3 - Evolução dos custos pela fase de intervenção (SITTER, 1984)

Acerca da importância da manutenção em edificações, pode-se apresentar o edifício em Fortaleza (Figura 4) que desabamento provocando diversas mortes. Ocorre que, as investigações apontam para causas que governaram o sinistro: a ausência de manutenções (fundamental); corrosão das armaduras de alguns pilares e deterioração do concreto.

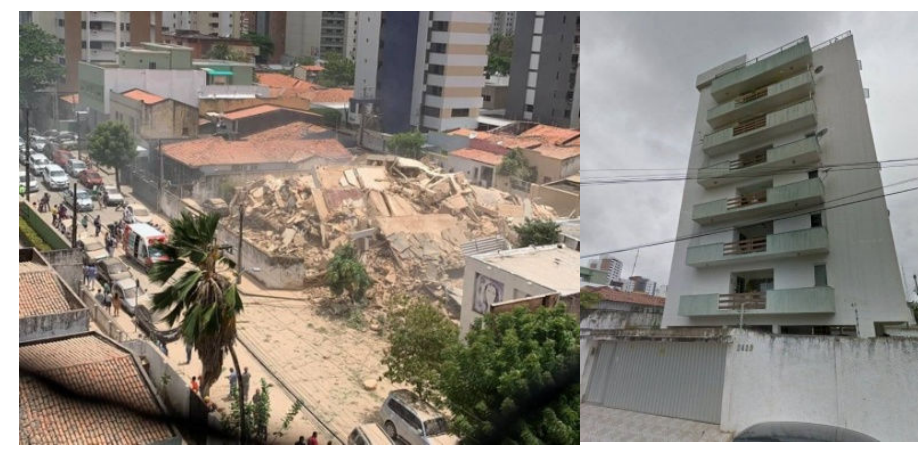

Figura 4 - Prédio que desabou em 2019 (Fortaleza/CE)

Segundo Souza e Ripper (1998), a corrosão de armaduras no concreto armado é um fenômeno de natureza eletroquímica, que pode ser acelerado pela presença de agentes agressivos externos ou internos incorporados ao 
concreto. Para que a corrosão se manifeste é necessário que haja oxigênio, umidade e o estabelecimento de uma célula de corrosão eletroquímica que só ocorre após o rompimento da camada passivadora da armadura (TAPAN e ABOUTAHA, 2011). A escolha dos materiais e da técnica de correção a ser empregada depende do diagnóstico do problema, das características da região e das exigências de funcionamento do elemento a ser corrigido. O comportamento em serviço é o resultado do trabalho desenvolvido nas etapas de projeto, construção e manutenção (SHI et al., 2012).

\section{METODOLOGIA:}

A pesquisa foi realizada a partir de vistorias de uma única edificação estudada no caso, ou seja, um prédio tipo caixão contendo estrutura de concreto armado central para a escada e o reservatório superior de água. Vale ressaltar que, as manifestações patologias encontradas no caso, também foram encontradas em diversos outros prédios análogos, com grau de degradação semelhante ao que se verificou nesse estudo.

O planejamento da pesquisa passou pela catalogação realizada na inspeção visual de toda estrutura central de concreto armado contido no prédio estudado [desde o pavimento térreo até o terceiro pavimento mais o reservatório superior de água (lajes, vigas e pilares)], com um rico acervo fotográfico diante dos aspectos, a saber:

patologias: classificação dos níveis de deterioração, segundo CEB (1983);

verificação da presença de carbonatação, mediante aspersão de fenolftaleína;

$$
\text { verificação da presença de cloretos, mediante aspersão de nitrato de prata. }
$$

Foram avaliados os elementos específicos (Vigas, pilares, lajes), onde por não conhecer os projetos dessa construção, buscou-se entrevistar o engenheiro da prefeitura local, conhecedor de informações próprias da obra. Nessa premissa, foram coletados dados sobre a idade das peças em serviço e resistência mecânica estimada, sendo esta tem $15 \mathrm{MPa}$ e aquela 33 anos (THOMÉ, 2017).

Portanto, foram estabelecidos níveis de deterioração de "A até E", em conformidade com o boletim 162 do CEB (1983), pois estabelece o grau de deterioração e a urgência na intervenção corretiva dos elementos estruturais em concreto armado.

\section{RESULTADOS E ANÁLISE}

As figuras 5 a 9 mostram as condições, de forma geral, das peças estudadas.

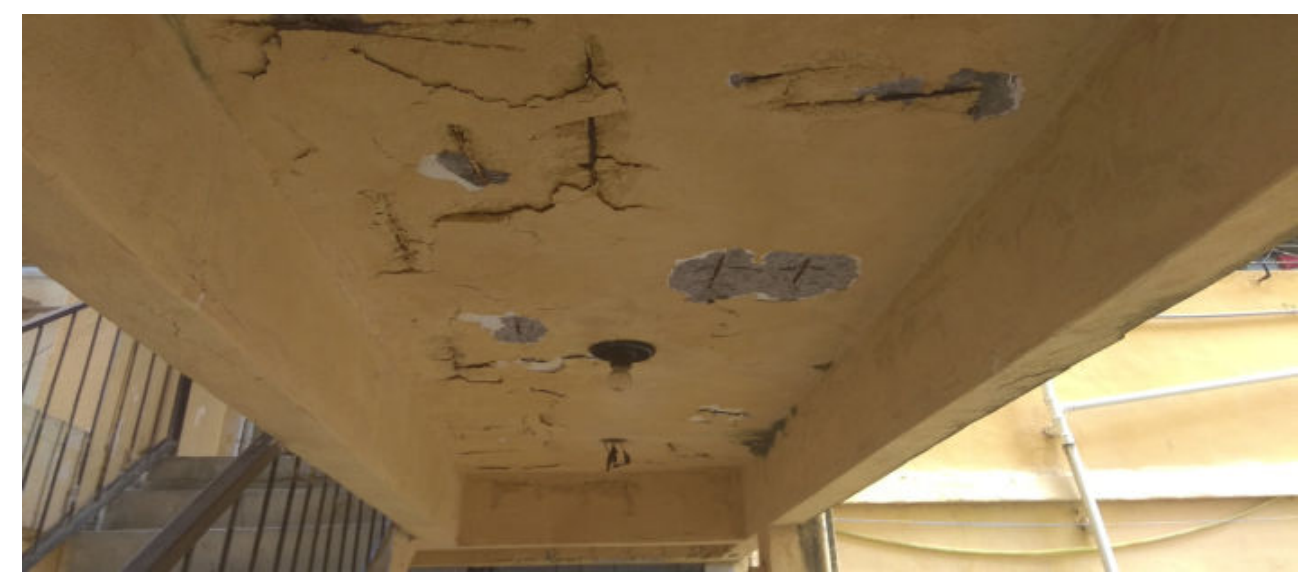

FIGURA 5 - CONCRETO E ARMADURA DA LAJE DO PATAMAR COM LASCAMENTO E OXIDAÇÃO 

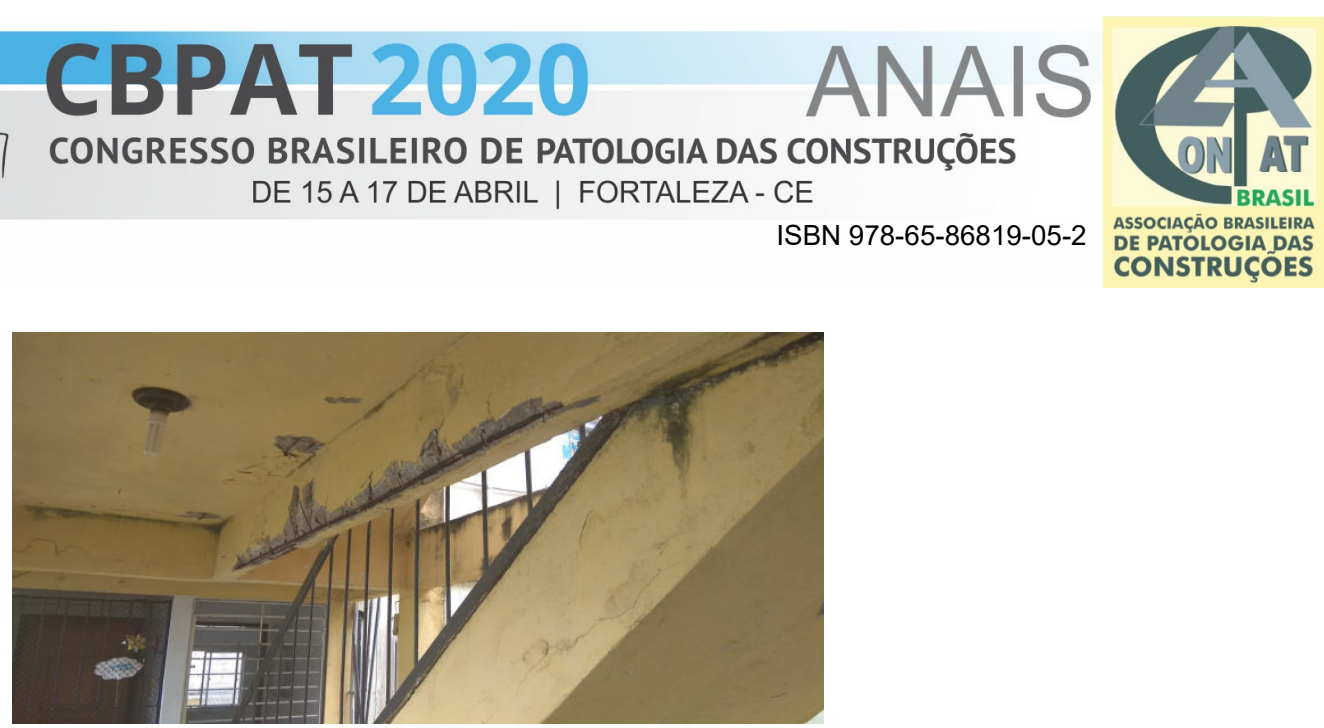

FIGURA 6 - VIGA DA ESCADA DETERIORADA

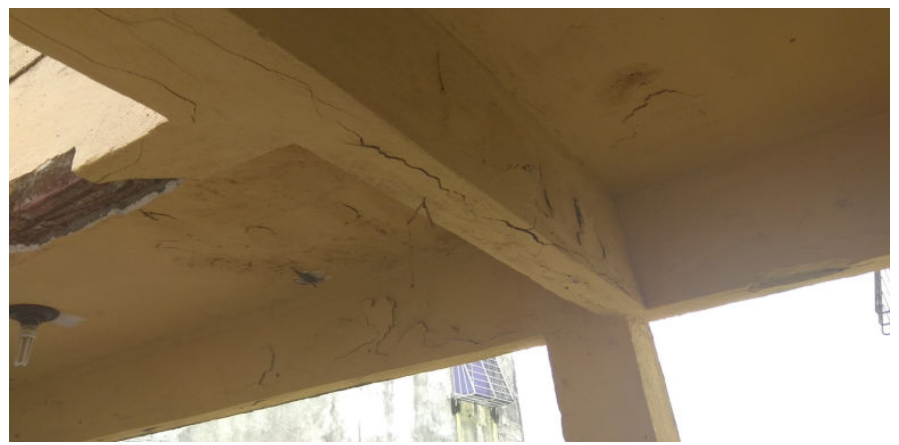

FIGURA 7 - FISSURAS NO CONCRETO EM VIGAS E LAJE DA ESCADA

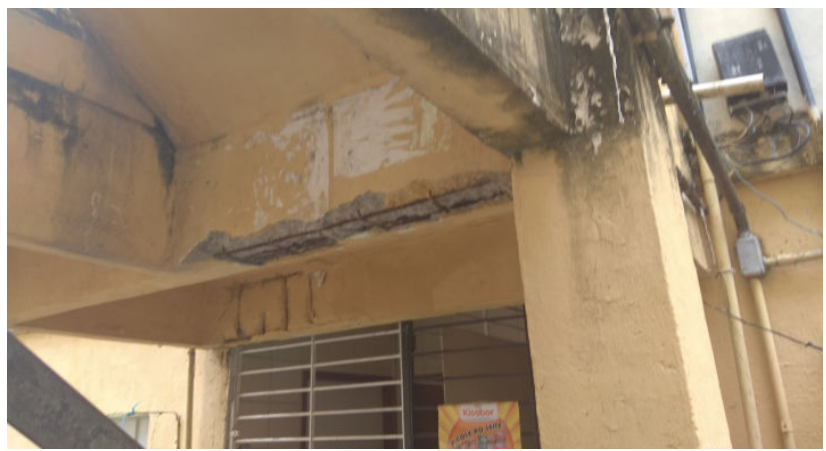

Figura 8 - Deterioração das vigas da caixa de escada no pavimento térreo

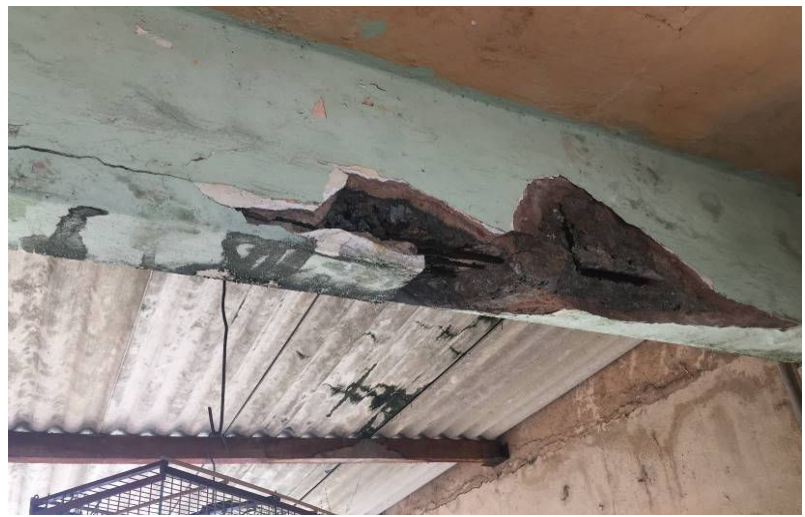

Figura 9 - Vigas da estrutura do reservatório superior com desplacamento e oxidação das armaduras

A Tabela 1 apresenta resultados médios dos danos catalogados por grupo de elementos estruturais analisado, com as causas prováveis. Todas as peças de todos os 4 (quatro) pavimentos mais a caixa de água superior foram analisadas. 


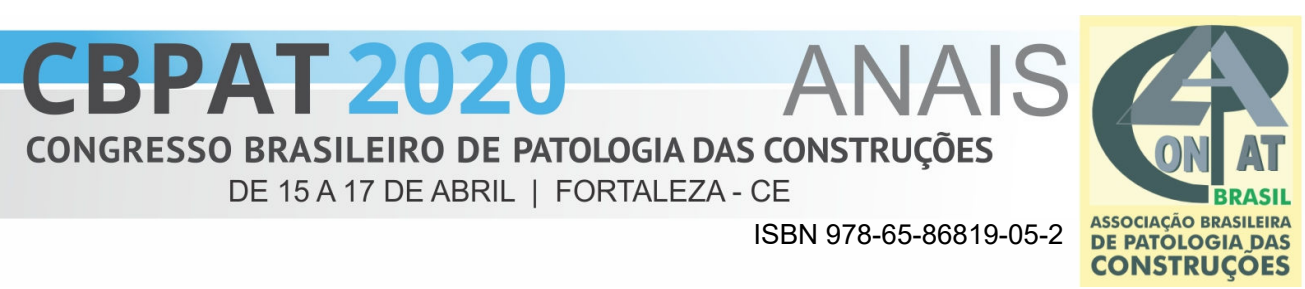

Tabela 1 - Catalogação de danos

\begin{tabular}{|c|c|c|c|}
\hline Elementos & Danos & Aspectos identificados & Causas prováveis \\
\hline \multirow{4}{*}{ Viga reservatório } & Bolor & Manchas escurecidas. & Elevada umidade. \\
\hline & $\begin{array}{l}\text { Desplacamento } \\
\text { do concreto }\end{array}$ & Grandes rachaduras do concreto. & Corrosão da armadura . \\
\hline & $\begin{array}{l}\text { Manchas de } \\
\text { corrosão }\end{array}$ & Manchas avermelhadas na região da armadura. & $\begin{array}{l}\text { Cobrimento deficiente, armaduras expostas e } \\
\text { com perda elevada da seção. }\end{array}$ \\
\hline & Ruína & Indicação de possibilidade de colapso. & $\begin{array}{c}\text { Cobrimento e seção da armaduraa reduzidos. } \\
\text { Região central dos vãos com flexão } \\
\text { excedente. }\end{array}$ \\
\hline \multirow{3}{*}{ Pilares } & Bolor & Manchas escurecidas. & Elevada umidade. \\
\hline & Desplacamento & Rachaduras significativas. & Corrosão da armadura com alto grau. \\
\hline & $\begin{array}{l}\text { Manchas de } \\
\text { corrosão }\end{array}$ & Manchas avermelhadas na região da armadura. & $\begin{array}{l}\text { Cobrimento deficiente, armaduras expostas e } \\
\text { com perda elevada da seção. }\end{array}$ \\
\hline \multirow{3}{*}{ Laje reservatório } & Bolor & Manchas escurecidas. & Elevada umidade. \\
\hline & $\begin{array}{l}\text { Desplacamento } \\
\text { do concreto }\end{array}$ & Rachaduras generalizada. & Corrosão da armadura generalizada. \\
\hline & $\begin{array}{l}\text { Manchas de } \\
\text { corrosão }\end{array}$ & Manchas avermelhadas na região da armadura. & $\begin{array}{l}\text { Cobrimento deficiente, armaduras expostas e } \\
\text { com perda elevada da seção. }\end{array}$ \\
\hline \multirow{4}{*}{$\begin{array}{l}\text { Vigas das } \\
\text { escadas }\end{array}$} & Bolor & Manchas escurecidas. & Elevada umidade. \\
\hline & $\begin{array}{l}\text { Rachaduras em } \\
\text { geral }\end{array}$ & Grandes lascamentos. & $\begin{array}{l}\text { Corrosão da armadura com alto grau de } \\
\text { expansão. }\end{array}$ \\
\hline & $\begin{array}{l}\text { Manchas de } \\
\text { corrosão }\end{array}$ & Manchas avermelhadas na região da armadura & $\begin{array}{l}\text { Cobrimento deficiente, armaduras expostas e } \\
\text { com perda elevada da seção. }\end{array}$ \\
\hline & Ruína & Colapso da estrutura premente. & $\begin{array}{l}\text { Cobrimento reduzido e perda de quase toda } \\
\text { seção da armadura. }\end{array}$ \\
\hline \multirow{3}{*}{$\begin{array}{l}\text { Laje da área } \\
\text { comum }\end{array}$} & Bolor & Manchas escurecidas. & Elevada umidade. \\
\hline & $\begin{array}{l}\text { Desplacamento } \\
\text { do concreto }\end{array}$ & Grandes rachaduras do concreto. & $\begin{array}{l}\text { Corrosão da armadura com alto grau de } \\
\text { expansão no interior do concreto. }\end{array}$ \\
\hline & $\begin{array}{l}\text { Manchas de } \\
\text { corrosão }\end{array}$ & Manchas avermelhadas na região da armadura. & $\begin{array}{c}\text { Cobrimento deficiente, armaduras expostas, } \\
\text { com perda elevada da seção. }\end{array}$ \\
\hline
\end{tabular}


Sabe-se que, colaboraram para as manifestações patológicas das peças, os fatores ambientais, ausência de manutenções e intervenções pontuais sem controle e tecnologia.

Remete-se a inspeção visual aos níveis de deterioração dos elementos de concreto armado, em conformidade com o boletim 162 do CEB (1983). Esse boletim estabelece níveis de deterioração de A até E, onde a partir dos níveis C e D, a intervenção deverá ser imediata, tendo em vista a ocorrência do esgotamento quase que integral da vida útil da peça estrutural.

Nesta ótica, a seguir apresentar-se-ão as considerações de análise média por grupo de elementos segundo o CEB (1983).

a) Vigas da estrutura do reservatório superior - Nível "E”;

b) Pilares de toda estrutura (escada mais reservatório superior) - Nível " $D$ ”;

c) Laje do reservatório superior - Nível "C";

d) Vigas da escadas - Nível "E";

e) Laje da escada e patamar da área comum - Nível "C";

Acerca da análise dos teores de cloretos, a principal contribuição do método colorimétrico seria a determinação da presença de cloretos diante da reação fotoquímica, onde havendo presença de cloretos livres ocorreria um precipitado claro (cloreto de prata), e, mais escuro (amarronzado) - cloretos combinados (MOTA, 2011, VAL e STEWART, 2003).

Portanto, verificou-se ao aspergir a solução de nitrato de prata que não houve qualquer reação fotoquímica (Figura 10), eliminando a possibilidade da presença de cloretos. Isso corrobora com Pontes et al. (2007), haja vista que a uma distância do mar de $3600 \mathrm{~m}$ aproximadamente como encontra-se a edificação estudada, os íons cloretos advindos da névoa salina não são operantes, pois sua ação deletéria ocorre quando a estrutura encontra-se até $450 \mathrm{~m}$ do mar.

Nessa premissa, não se observou ataque de cloretos à camada passiva da armadura que ocasionasse corrosão pontual conhecida como pite, despassivando a armadura (MOTA, 2009, SIAMPHUDKEE et al., 2013).

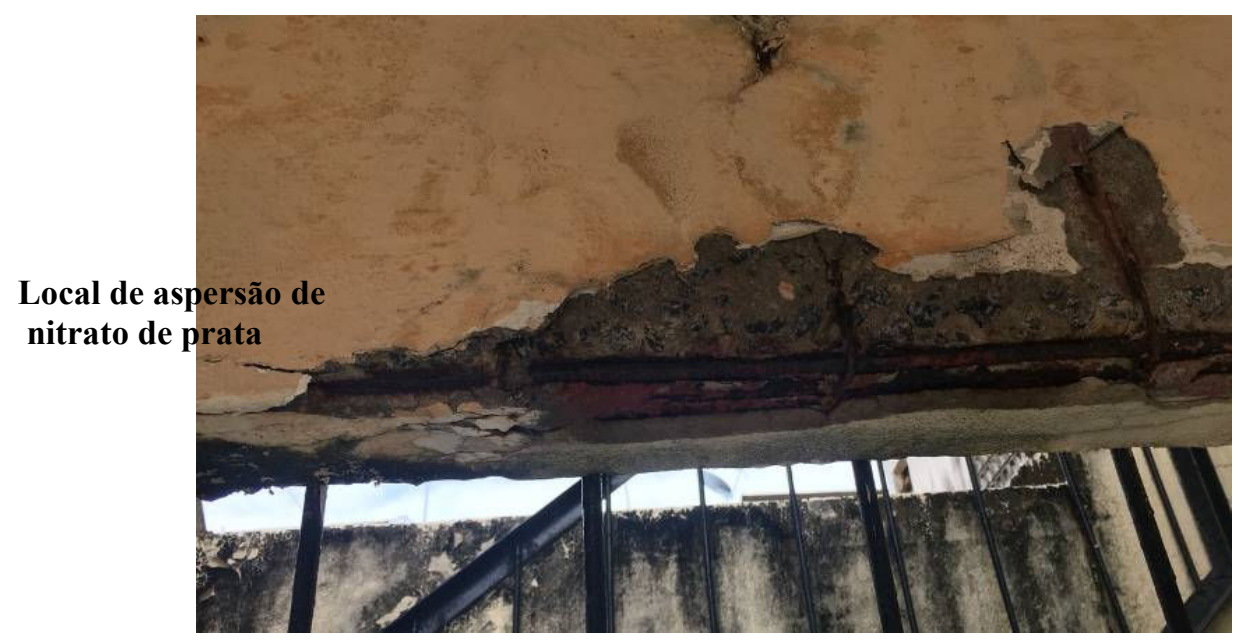

Figura 10 - Viga após aspersão de nitrato de prata

Por sua vez, a carbonatação que ocorre nos interstícios do concreto saturado de hidróxido de cálcio e de outros compostos alcalinos hidratados, recebe o nome de carbonatação pela relação do hidróxido de cálcio $\mathrm{Ca}(\mathrm{OH})_{2} \mathrm{com} \mathrm{CO}_{2}$, resultando em carbonato de cálcio $\left(\mathrm{CaCO}_{3}\right)$. Esta molécula sendo lixiviada para o exterior da peça do concreto (superfície), precipitam-se manchas esbranquiçadas chamadas de eflorescência. Portanto, esse fenômeno se estabelecendo, veias de poros se formam, de tal maneira que torna-se uma condição altamente desfavorável por ser caminho adequado à penetração de agentes deletérios (CADORE, 2008). 
Em campo, para diagnosticar a carbonatação nas estruturas de concreto armado, foi aplicado por aspersão uma solução com $1 \%$ de fenolftaleína, $70 \%$ de álcool etílico e $29 \%$ de água destilada. O intervalo da mudança de cor da solução desta solução situa-se numa faixa de $\mathrm{pH}$ entre 8,3 e 10, isto é, quando a cor encontrada for vermelho-carmim o concreto apresenta-se não carbonatado, entretanto, caso fique incolor, de fato, o concreto está carbonatado (Basset et al., 1981, ).

Entretanto, diferentemente do teor de cloretos, verificou-se que o nível de carbonatação (ataque da estrutura por $\mathrm{CO}_{2}$ ) na maioria dos casos mostrou-se elevado, tendo em vista que foi verificado sempre incolor, indicando a carbonatação como um dos agentes deletérios causadores de parte das manifestações patológicas encontradas na edificação.

Esta constatação alinha-se a diversas pesquisas que reportam a carbonatação como fator importante da deterioração de compósitos cimentícios (MOTA, 2015).

A Figura 11 mostra o comportamento da estrutura após ser submetida à aspersão de Fenolftaleína.

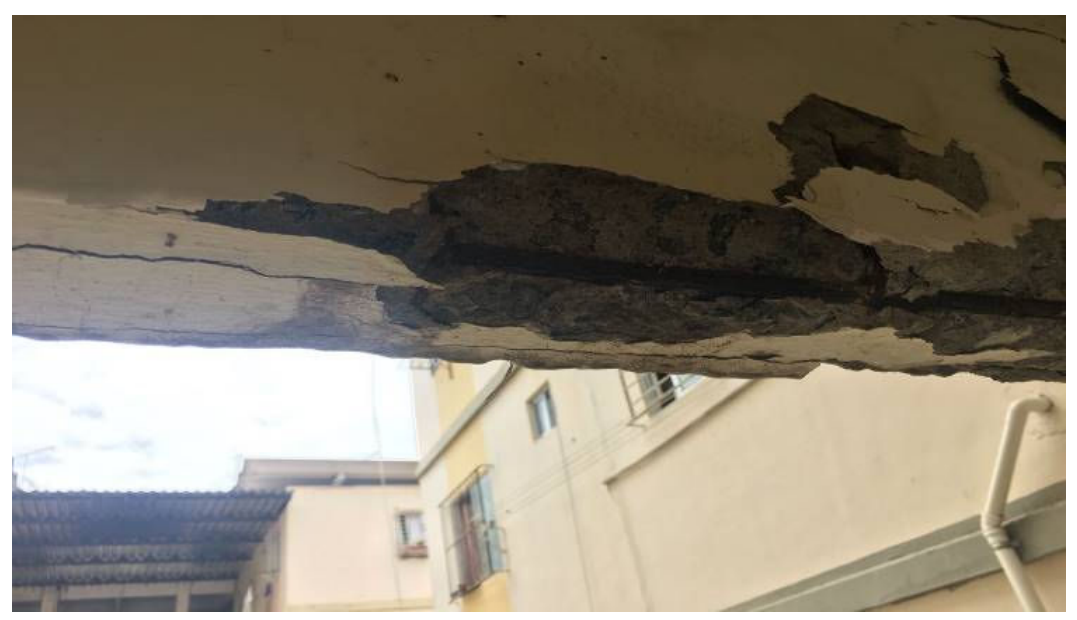

Figura 11 - Viga após aspersão de Fenolftaleína

Ademais, trincas, fissuras e manchas no concreto podem indicar problemas nas edificações que não devem ser ignorados e merecem reparo. Quando uma estrutura apresenta tais patologias, deverá ser analisada e, se preciso reparada, identificando as causas e origens das manifestações e aplicando a técnica de recuperação adequada, diante de projeto específico produzido por profissional notadamente qualificado (BRITO, 2017).

Não obstante, o resultado das investigações apontam que praticamente todas as peças de concreto armado programado para avaliação, ou seja, a estrutura central encontram-se com algum tipo de dano, estando aparentemente preservadas, menos de $10 \%$ das peças. Portanto, a carbonatação e, fundamentalmente a umidade, são fatores que governam à baila.

\section{CONSIDERAÇÕES FINAIS/CONCLUSÕES:}

A necessidade de se realizar manutenções preventivas e corretivas, torna-se evidente a partir da análise do grau de deterioração pela qual se encontra a edificação tipo caixão do estudo. Portanto, a importância deste estudo de caso, buscou identificar as manifestações patológicas pertinentes, catalogando suas prováveis causas, tendo em vista que grande parcela da população desconhece os riscos que correm em não realizar reparos e manter, de maneira satisfatória, a manutenção de suas residências.

A possível falta de organização no que se diz respeito à regulamentação de um condomínio e da criação do cargo de síndico, corrobora de maneira significativa para dificuldade de se executar manutenções, uma vez que se têm informações que grande parcela dos edifícios populares da região apenas taxam seus condôminos à quantia suficiente para pagamento de água e luz, não sendo possível deixar nenhuma reserva financeira para manutenção, reparos e melhorias estruturais. 
Constatou-se na análise visual diante da literatura científica (CEB, 1983), a necessidade de reabilitações nos elementos estruturais estudados, ou seja, as peças de concreto apresentavam níveis de deterioração elevados (níveis "C, D e E”), indicando que a vida útil se encontra praticamente esgotada.

Foi possível verificar que na maioria dos casos, a elevada umidade contribuiu significativamente para o estabelecimento de um microclima desfavorável para oxidação das armaduras e, por conseguinte, com sua expansão, desplacando o concreto, rachando-o, e, aguçando a condição de penetração de agentes agressivos.

Não foi identificado presença de cloretos nas peças de concreto estrutural analisadas, haja vista inalteração da coloração após aspersão de nitrato de prata em região do concreto com elevada deterioração. Por conseguinte, a distância elevada do mar, justifica não se verificar ação dos íons cloretos.

Verificou-se que, na maioria dos grupos de elementos estruturais analisados, o ataque do dióxido de carbono, uma vez que após a aspersão da solução de fenolftaleína em regiões com elevada deterioração, observou-se inalteração da coloração, caracterizando áreas carbonatadas.

Portanto, a carbonatação, a umidade e a ausência de manutenções preventivas e corretivas, foram os agentes desfavoráveis que governaram as manifestações patológicas apresentadas nas lajes, vigas e pilares da estrutura específica estudada.

Por fim, pode-se contribuir inferindo que, tais condições conduz a necessidade de intervenção do poder público nessas edificações popular, na medida em que a não realização das correções dessas manifestações patológicas, pode levar ao colapso da estrutura, pondo em risco a vida de inúmeras famílias.

\section{REFERÊNCIAS}

ANDRADE, J. J. O. Durabilidade das estruturas de concreto armado: análise das manifestações patológicas nas estruturas no estado de Pernambuco. Dissertação (Mestrado em Engenharia Civil) - Universidade Federal de Goiás. Goiás, 1997.

ANDRADE, M. C. P. Manual para diagnóstico de obras deterioradas por corrosão de armaduras. 1.ed. PINI. São Paulo, 1992.

ASSOCIAÇÃO BRASILEIRA DE NORMAS TÉCNICAS. NBR 6118: (2014) projeto de estruturas de concreto: procedimento. Rio de Janeiro.

BASSET et al. Análise inorgânica quantitativa. Editora Guanabara. Rio de Janeiro, 1981.

BRITO, T. Análise de manifestações patológicas na construção civil pelo método GUT: estudo de caso em uma instituição pública de ensino, João Pessoa-PB, 2017.

CADORE, W. W. Estudo da carbonatação da camada de cobrimento de protótipos de concreto com altos teores de adições minerais e cal hidratada. Dissertação de mestrado UFSM, Universidade federal de Santa Maria, Santa Maria-RS, 2008.

COMDEC. Aspectos jurídicos das atividades da defesa civil. Disponível em: http://www.mi.gov.br/c/document_library/get_file?uuid=1b7fc012-b6d8-4feb-be2a-c0c9f589287f\&groupId=10157.

Brasilia, 2007.

COMITE EURO INTERNATION DU BETON - CEB Assessment of concrete structures and design procedure for upgrading (redesign). Paris, Bulletin, 1983.

CORSINI, R. Ambientes agressivos. Téchne: São Paulo, 2013. Edição 196. Disponível em: http://techne.pini.com.br/engenharia-civil/196/ambientes-agressivos-projetos-de-estruturas-de-concreto-expostas-a294033-1. aspx . Acesso em: 31 de abr. de 2017. 
FIGUEIREDO, A. Análise das manifestações patológicas em estrutura de concreto em prédio tipo "caixão" da Região Metropolitana de Recife. Trabalho de conclusão de curso para bacharelado em engenharia civil no Instituto Federa de Pernambuco. Recife, 2019.

HELENE, P. R. L. Manual Prático para Reparo e Reforço de Estruturas de Concreto. Editora PINI. São Paulo, 1992.

HELENE, P. R. L. Vida útil das estruturas de concreto. In: IV CONGRESSO IBEROAMERICANO DE PATOLOGIA DAS CONSTRUÇÕES. Porto Alegre, 1997.

LIMA A. O., BRITO V. L. Plano de manutenção de estruturas de concreto armado sujeitas a agressividade marinha: estudo de caso no porto de Cabedelo-PB. Cabedelo-PB, 2016.

MOTA, A. C. M. Avaliação da presença de cloretos livres em argamassas através do método colorimétrico de aspersão da solução de nitrato de prata. Dissertação (mestrado). Escola Politécnica da Universidade de Pernambuco, Recife, Brasil, 2011.

MOTA J. M. Notas de Aula da Disciplina: Patologia das construções - graduação em engenharia civil, IFPE Instituto Federal de Pernambuco. Recife, 2017.

MOTA J. M. Reforço de Alvenaria Resistente com Argamassa Armada com Adição de Metacaulim. Tese de Doutorado pela UFPE. Recife, 2015.

MOTA, J. M. F; Dourado K. C.; Barbosa F. R; Costa e Silva A. J.; Carvalho J. R. Physical and Chemical Properties of poured concrete with pozzolan metakaolin and prevention against alkali aggregate reaction (AAR). Ibracon. Florianópolis, 2011.

MOTA J. M. F., PONTES, R. B., CANDEIAS NETO, J. A., OLIVEIRA M. F., ALMEIDA H. T., CARNEIRO A. M. $P$. Análise das patologias em estruturas de concreto na zona litorânea da cidade do Recife-PE. X Congresso Latino-americano de Patologia e XII Congresso de qualidade da construção. CONPAT 2009. Valparaíso-Chile, 2009.

PONTES, R. B.; MONTEIRO, R. A.; OLIVEIRA, R. A.; PAIVA, S. C. Levantamento da concentração de cloretos em zona costeira do Recife-PE. IX CONGRESSO LATINOAMERICANO DE PATOLOGIA. Quito - Equador, 2007.

SHI, X.; XIE, N.; FORTUNE, K.; GONG, J. Durability of steel reinforced concrete in chloride environments: An overview. Construction and Building Materials, 2012.

SIAMPHUDKEE, K.; COLLINS, F., ZOU, R. Sensitivity analysis of corrosion rate prediction models utilized for reinforced concrete affected by chloride. Journal of Materials Engineering and Performance, 2013.

SOUZA, V. C.; RIPPER, T. Patologia, recuperação e reforço de estruturas de concreto. São Paulo: Pini, 1998.

TAPAN, M.; ABOUTAHA, R.S. Effect of steel corrosion and loss of concrete cover on strength of deteriorated RC columns. Construction and Building Materials, 2011.

THOMÉ, R. W. (2017) Engenheiro civil da Prefeitura da Cidade do Paulista - Entrevista concedida a Augusto Magno Leal de Figueiredo. Paulista, Agosto, 2017.

VAL, D.V.; STEWART, M.G. Life-cycle cost analysis of reinforced concrete structures in marine environments. Structural Safety, 2003. 